\title{
Estudo sobre os vencimentos de professores da rede estadual de São Paulo (1996-2014)
}

\author{
Study on the remuneration of teachers from the state network of São Paulo \\ (1996-2014) \\ Estudio sobre los vencimentos de profesores de la red estatal de São Paulo \\ (1996-2014)

\section{RUBENS BARBOSA DE CAMARGO JOÃO BATISTA DA SILVA DOS SANTOS JOSÉ QUIBAO NETO}

\begin{abstract}
Resumo: $\mathrm{O}$ presente artigo tem por objetivo analisar os vencimentos dos professores da Rede Estadual de Ensino de São Paulo (REE/SP). Para compreender essa parte da remuneração dos docentes da rede estadual paulista, o artigo analisa o vencimento inicial e o final no período de 1996 a 2014, sua evolução e correlações entre si. Ainda, para aprofundar o debate e as comparações, o artigo considera as relações entre os vencimentos da REE/SP com o Piso Salarial Profissional Nacional do Magistério Público da Educação Básica e com os vencimentos registrados em redes de outros estados, comparando e mostrando em que posição, em termo de vencimentos pagos aos docentes, encontra-se nacionalmente a REE/SP. Por fim, relacionar-se-á a evolução dos vencimentos da REE/SP com os indicadores salariais "Salário Mínimo" e "Salário Mínimo Necessário".
\end{abstract}

Palavras-chave: Rede estadual de ensino de São Paulo; vencimentos; remuneração docente.

Abstract: The purpose of this article is to analyze the salaries of the teachers of the São Paulo State Educational Network (REE / SP). In order to understand this part of the remuneration of teachers in the state of São Paulo, the article analyzes the initial and final maturity in the period from 1996 to 2014, its evolution and the correlations between them. To go deeper on the debate and comparisons, the article considers the relationships between the salaries of the REE / SP with the National Minimum Salary of the Public Teaching of Basic Education and with the salaries registered in other state networks, comparing and showing in which position the REE / SP nationally is in terms of salaries paid to teachers. Finally, the evolution of the salaries of the REE / SP with the salary indicators will be related: Minimum Wage and Minimum Wage Required.

Keywords: State educational network of São Paulo; salaries; teacher's remuneration.

Resumen: El presente artículo tiene por objetivo analizar los vencimientos de los profesores de la Red Estatal de Enseñanza de São Paulo (REE/SP). Para comprender esa parte de la remuneración de los docentes de la red estatal paulista, el artículo analiza el vencimiento inicial y final en el periodo de 1996 a 
2014, su evolución y correlaciones entre sí. Todavía, para profundizar el debate y las comparaciones, el artículo considera las relaciones entre los vencimientos de la REE/SP con el Suelo Salarial Profesional Nacional de Magisterio Público de la Educación Básica y con los vencimientos registrados en redes de otros estados, comparando y presentando en cuál posición se encuentra la REE/ SP nacionalmente con relación a los vencimientos pagos a los docentes. Por fin, se va a relacionar la evolución de los vencimientos de la REE/SP con los indicadores salariales: Sueldo Mínimo y Sueldo Mínimo Necesario.

Palabras clave: Red estatal de enseñanza de São Paulo; vencimientos; remuneración docente.

\section{INTRODUÇÃO}

A Rede Estadual de Ensino de São Paulo (REE/SP) destaca-se por ser uma das maiores redes do Brasil. Para citar como exemplo, no ano de 2014, considerando-se sua dimensão, a rede atendia na Educação Básica 4.217.246 matrículas, espalhadas em 5.666 estabelecimentos, contando com 249.209 professores, dos quais 138.671 eram efetivos e 110.538 não efetivos (configurados respectivamente, como profissionais "estáveis" e "temporários").

Em termos de recursos públicos, o estado de São Paulo possui a segunda maior arrecadação do país, perdendo em grandeza apenas para a União. Dentro do estado, são 645 municípios, com renda per capita mensal média de $\mathrm{R} \$ 1.480,00$, inferior somente ao Distrito Federal. Isso garante ampla receita destinada à educação em comparação aos outros estados brasileiros. Um notável exemplo é o Fundo de Manutenção e Desenvolvimento da Educação Básica e de Valorização dos Profissionais da Educação (Fundeb) que, segundo o Sistema de Informação sobre Orçamentos Públicos em Educação (Siope), obteve em 2014 receita de R\$ 19,9 bilhões. No entanto, os repasses obrigatórios de recursos financeiros aos municípios, pela via do Fundeb, fizeram a Rede Estadual de Ensino de São Paulo "perder" 22,3\% de seu orçamento destinado à educação naquele ano (QUIBAO NETO, 2015). Isso indica que, mesmo sendo o Estado de São Paulo um dos maiores arrecadadores do Brasil, ainda assim, o efeito das transferências de receita para os municípios é grande, resultando em menos recursos disponíveis para serem gastos com a REE/SP, em especial, na remuneração adequada de seus docentes.

No campo político-institucional, destaca-se a permanência de um único partido político há 26 anos no poder, o Partido da Social Democracia Brasileira (PSDB), que, após várias eleições e reeleições, realizou mudanças significativas na rede; uma delas foi a municipalização dos primeiros anos do Ensino Fundamental, no início dos anos 1990 (ARELARO, 2005), antecipando o Fundo de Manutenção 
e Desenvolvimento do Ensino Fundamental (Fundef), o que gerou no decorrer da década a descentralização das matrículas e dos recursos para os municípios e descontinuou uma rede educacional que tendia a ser única no estado.

Dada a complexidade apresentada, são de se esperar estudos sobre a REE/SP e as políticas públicas que a impactaram. Nesse sentido, este trabalho é uma colaboração para o entendimento da remuneração dos professores que atuam na rede de ensino em questão, em particular sobre seus vencimentos, recortando o período de 1996 a 2014, aprofundando os estudos sobre essa questão.

Vale destacar, ainda, que este artigo é resultado de estudos da Pesquisa "Observatório da Remuneração Docente", pesquisa nacional cujo objetivo é contribuir com suas análises para o intricado funcionamento dos salários dos professores das redes básicas de ensino.

No caso deste artigo, os dados utilizados foram coletados dos documentos oficiais nacionais e estaduais de São Paulo, configurados em gráficos e tabelas elaborados pelos autores para facilitar a visualização permitindo melhor descrição e análise, sendo todos os dados corrigidos pelo Índice Nacional de Preços ao Consumidor $^{2}$ (INPC) até de dezembro de 2014.

\section{DINÂMICA DOS VENCIMENTOS DOS DOCENTES DA REDE ESTADUAL DE SÃO PAULO DE 1996 A 2014}

O "salário-base" é o valor da retribuição pecuniária por serviço prestado ao Estado de São Paulo. Normalmente, no setor educacional público, ele é garantido e regulamentado em tabela anexa às leis que tratam dos planos de carreira, cargos e remuneração (PCCR). Essa parte do salário, chamada "saláriobase" compõe a remuneração dos professores conjuntamente com vantagens (fixas e variáveis), também estabelecidas em forma de valor. Assim como na maior parte das redes públicas no Brasil, o salário-base dos professores da REE/SP é o valor mais expressivo da remuneração docente; portanto, representa os maiores valores nas folhas de pagamento (JACOMINI; MINHOTO; CAMARGO, 2012;

\footnotetext{
1 Pesquisa financiada segundo o Edital no 08/2012 da Capes/Inep/Secad - Observatório da Educação - realizada no âmbito de 12 Estados, e que em São Paulo é realizada em cooperação da Universidade de São Paulo (USP) com a Universidade Federal de São Paulo (UNIFESP). Para mais informações acessar site da pesquisa $<$ http://observatorioderemuneracaodocente.org/>.

2 INPC se baseia na variação de rendimento que se entende como necessária para a manutenção do padrão de vida de famílias que recebem entre um) e cinco salários mínimos, ou seja, para famílias que têm como chefe um assalariado com renda entre $\mathrm{R} \$ 880,00$ e $\mathrm{R} \$ 4.400,00$, o que permite que adotemos tal índice para as devidas análises.
} 
QUIBAO NETO, 2015). Importante é destacar que essa parte da remuneração também é amplamente conhecida pelos professores e estudiosos do assunto como "vencimento".

Em geral, nas carreiras docentes pelo Brasil, o vencimento costuma caracterizar-se em tabelas ou quadros organizados de acordo com as seguintes variáveis: formação, tempo de serviço, participação em atividades e cursos de formação continuada, avaliação de desempenho e etapa de ensino. Particularmente na REE/SP, o valor do vencimento difere para professores com formação em nível médio na modalidade Normal e para professores especialistas, isto é, que têm formação de nível superior em Pedagogia ou Licenciatura Plena em diferentes áreas de conhecimento. Assim, conforme o professor aumenta sua capacitação e seu tempo de serviço, ele se movimenta na tabela de vencimentos de forma crescente, segundo mostram Jacomini, Minhoto e Camargo (2012):

Em geral, os valores de vencimento estão descritos em normas, em uma tabela de dupla entrada que relaciona o enquadramento funcional e a posição ocupada pelo servidor, em virtude de sua movimentação na carreira - chamada, entre outras expressões, de evolução, progressão e promoção. A movimentação pode ocorrer em qualquer direção, vertical ou horizontal, em geral, de forma sempre crescente. Em outras palavras, o vencimento está descrito em um quadro de valores financeiros associados à posição e ao enquadramento de um servidor público em determinada classe administrativa. (JACOMINI; MINHOTO; CAMARGO, 2012, p. 3).

A fim de averiguar os valores dos vencimentos para os docentes da REE/SP e as mudanças que ocorreram, mostramos na tabela 1 os vencimentos iniciais (VI) e vencimentos finais (VF)dos docentes da REE/SP referentes ao mês de outubro de cada ano, considerando a formação tanto para Ensino Médio na modalidade Normal e quanto para as diferentes Licenciaturas Plenas (os quais também indicam o valor de "final de carreira" para os docentes), para uma jornada padrão de 40 horas semanais (uma das possíveis da REE/SP), separados por mandatos dos governadores no período de 1996 a 2014. 
Tabela 1 - Vencimentos iniciais e finais dos docentes da rede estadual de ensino (1996-2014), por mandatos dos governadores - em $\mathbf{R} \$$ de dez./2014.

\begin{tabular}{|c|c|c|c|c|c|c|}
\hline & Habilitação & $\begin{array}{c}\text { Ensino } \\
\text { Médio } \\
\text { (PI e PEB I) }\end{array}$ & $\begin{array}{c}\text { Ensino } \\
\text { Médio } \\
\text { (PI e PEB I) }\end{array}$ & $\begin{array}{l}\text { Licenciatura } \\
\text { (PIII e PEB } \\
\text { II) }\end{array}$ & $\begin{array}{c}\text { Licenciatura } \\
\text { (PIII e PEB } \\
\text { II) }\end{array}$ & $\begin{array}{l}\text { Final da } \\
\text { carreira } \\
\text { docente } \\
\end{array}$ \\
\hline \multirow[t]{2}{*}{ Governador } & & $\begin{array}{c}\text { Vencimento } \\
\text { Inicial }\end{array}$ & $\begin{array}{c}\text { Vencimento } \\
\text { Final }\end{array}$ & $\begin{array}{c}\text { Vencimento } \\
\text { Inicial }\end{array}$ & $\begin{array}{c}\text { Vencimento } \\
\text { Final }\end{array}$ & \\
\hline & $\begin{array}{c}\text { Carga } \\
\text { Horária }\end{array}$ & 40 & 40 & 40 & 40 & 40 \\
\hline COVAS 1 & 1996 & $1.043,02$ & $1.740,16$ & $1.247,88$ & $2.115,18$ & $2.115,18$ \\
\hline COVAS 1 & 1997 & 999,24 & $1.667,11$ & $1.195,50$ & $2.026,38$ & $2.026,38$ \\
\hline COVAS 1 & 1998 & $2.320,91$ & $2.821,05$ & $2.901,14$ & $3.526,34$ & $3.526,34$ \\
\hline COVAS 2 & 1999 & $2.189,82$ & $2.661,70$ & $2.737,27$ & $3.327,16$ & $3.327,16$ \\
\hline COVAS 2 & 2000 & $2.046,51$ & $2.487,52$ & $2.558,14$ & $3.109,42$ & $3.109,42$ \\
\hline COVAS 2 & 2001 & $1.906,90$ & $2.317,83$ & $2.383,63$ & $2.897,31$ & $2.897,31$ \\
\hline ALCKMIN 1 & 2002 & $1.827,20$ & $2.220,94$ & $2.283,99$ & $2.776,20$ & $2.776,20$ \\
\hline ALCKMIN 2 & 2003 & $1.554,89$ & $1.889,95$ & $1.943,60$ & $2.362,46$ & $2.362,46$ \\
\hline ALCKMIN 2 & 2004 & $1.663,83$ & $2.022,38$ & $1.926,08$ & $2.341,15$ & $2.341,15$ \\
\hline ALCKMIN 2 & 2005 & $1.822,40$ & $2.215,13$ & $2.109,64$ & $2.564,28$ & $2.229,79$ \\
\hline LEMBO & 2006 & $1.771,65$ & $2.153,44$ & $2.050,89$ & $2.492,87$ & $2.167,70$ \\
\hline SERRA & 2007 & $1.769,51$ & $2.150,84$ & $2.048,40$ & $2.489,85$ & $2.066,11$ \\
\hline SERRA & 2008 & $1.854,74$ & $2.254,43$ & $2.147,08$ & $2.609,78$ & $2.609,78$ \\
\hline SERRA & 2009 & $1.775,78$ & $2.158,45$ & $2.055,67$ & $2.498,68$ & $2.498,68$ \\
\hline GOLDMAN & 2010 & $1.773,57$ & $4.311,56$ & $2.053,12$ & $4.991,15$ & $4.991,15$ \\
\hline ALCKMIN 3 & 2011 & $1.975,93$ & $5.592,82$ & $2.287,38$ & $6.474,40$ & $6.474,40$ \\
\hline ALCKMIN 3 & 2012 & $2.063,39$ & $5.840,40$ & $2.388,64$ & $6.761,00$ & $6.761,00$ \\
\hline ALCKMIN 3 & 2013 & $2.110,86$ & $5.974,75$ & $2.443,59$ & $6.916,55$ & $6.916,55$ \\
\hline \multirow[t]{2}{*}{ ALCKMIN 3} & 2014 & $2.119,01$ & $5.997,84$ & $2.453,03$ & $6.943,28$ & $6.943,28$ \\
\hline & $\begin{array}{c}\text { \% Reaj. } \\
\text { Real } \\
\text { 1996-2014 }\end{array}$ & 103,16 & 244,67 & 96,57 & 228,26 & 228,26 \\
\hline
\end{tabular}

Fonte: Tabelas de vencimentos (anexos de legislação) - vários anos. Valores corrigidos pelo INPCIBGE para R\$ de dez./2014.

A partir dos dados apresentados na Tabela 1, o artigo se encaminhará para uma série de cálculos e análises que dizem respeito à dinâmica dos valores apresentados (valores mínimos e máximos, alterações etc.), às dispersões de valores em cada habilitação docente, à dispersão total da carreira docente, tentando associá-las aos respectivos governos do Estado (que apresentaram diferentes políticas de pagamento aos docentes no período).

Em uma descrição inicial dos dados apresentados, é importante perceber que os valores dos vencimentos iniciais (VI) do professor com formação de nível médio na modalidade Normal variaram de $\mathrm{R} \$ 1.043,20 \mathrm{em} 1996$ para $\mathrm{R} \$ 2.119,01$ em 2014, obtendo uma variação real no período de 103,16\%. Movimento 
semelhante ocorreu com os vencimentos iniciais dos licenciados, que, ao saírem de $R$ \$ 1.247,88 em 1996 e atingirem $R$ \$2.453,03 em 2014, sofreram uma variação positiva de $96,6 \%$.

Vale lembrar, no entanto, que tal movimento não é linear, pois é perceptível através dos dados que em 1996 e 1997 têm-se os menores valores das respectivas séries, com um aumento muito significativo em 1998, ano em que os vencimentos iniciais (tanto do nível médio, como dos licenciados) atingiram os maiores valores da série: respectivamente $\mathrm{R} \$ 2.320,91$ e $\mathrm{R} \$ 2.901,14$. Tal movimento nos vencimentos pode ser explicado pela Lei Complementar (LC) $n^{\circ}$ 836/97 implantada no Governo de Mario Covas I, com Rose Neubauer na Secretaria de Educação. A medida incorporou várias gratificações ao vencimento e reajustou valores; em contrapartida, a política adotada fez diminuir a possibilidade de evolução na carreira, estabelecendo apenas duas faixas (PEB I e PEB II) e somente cinco níveis horizontais ( $\mathrm{I} \mathrm{V}$ ). Assim, uma das consequências foi o aumento do vencimento inicial de docentes com ambos os níveis de formação, que foram elevados para os professores PEB I, como vieram a ser denominados os docentes que trabalhavam com as séries iniciais do Ensino Fundamental, em $132,7 \%$, e para os Professores PEB II, aqueles profissionais que trabalhavam com as séries finais do Ensino Fundamental e com o Ensino Médio, em 142,7\%.

Entretanto, nos anos seguintes, tal valorização nos valores dos vencimentos não foi mantida em termos reais ${ }^{3}$. Ao contrário do que foi visto no ano de 1998, os valores foram baixando gradativamente até atingir no ano de 2003, no governo Alckmin I, o segundo pior valor corrigido, quando o vencimento foi de $R \$ 1.554,89$ para os PEB I e de $R \$ 1.926,06$, no ano seguinte, para os PEB II. De 2004 em diante, houve oscilações reais, em alguns momentos negativas em outros positivas - os valores menores que $\mathrm{R} \$ 1.800,00$ aconteceram nos governos Lembo, Serra e Goldman para os PEB I; valores menores que R\$ 2.000,00 ocorreram nos anos de 2003 e 2004 no governo Alckmin II. Todavia, pode-se perceber que de 2011 a 2014 (governo Alckmin III) houve uma tendência de valores crescentes em termos reais dos vencimentos iniciais, passando de $\mathrm{R} \$$ $1.975,93$ para $R \$ 2.119,01$ para o PEB I e de $R \$ R \$ 2.287,38$ para 2.453,03 para os PEB II.

Ao nos debruçarmos sobre a análise dos vencimentos finais (VF) na REE/SP, importa ressaltar a prática comum de associá-los ao que se espera que os docentes estejam recebendo no seu período de aposentadoria. Nesse sentido,

\footnotetext{
3 É importante destacar que o vencimento na época ficou "congelado", isto é, não foi alterado seu valor nominal. Representa também que em termos reais seus valores são cada vez menores, porém pode ser que nos respectivos anos foram recriadas gratificações, adicionais, prêmios etc. para procurar mitigar tal procedimento e, minimamente, procurar manter o poder de compra dos docentes paulistas.
} 
o tempo total para atingir a posição final da tabela de vencimentos é um fator importante na caracterização do plano de carreira vigente. Para efeito de análise, os docentes demoram, em geral, entre 22 e 27 anos para atingir os vencimentos finais em suas respectivas carreiras.

$\mathrm{Na}$ tabela 1, é possível perceber que as mudanças nos valores dos vencimentos finais foram diferentes em relação aos vencimentos iniciais, majoritariamente por conta da legislação citada, que alterou as carreiras docentes. No ano de 1996, o vencimento final do PEB I foi de $\mathrm{R} \$ 1.740,16$, porém caindo no ano seguinte para $\mathrm{R} \$ 1.667,11$, o menor valor da série histórica (governo Covas). Porém, no ano de 1998 tal valor saltou para $\mathrm{R} \$ 2.821,05$, com um aumento real de 69,2 \%. Esse percentual apesar de considerável, é baixo quando comparado com o percentual de reajuste para o vencimento inicial (132, 7 \%) no mesmo período. Pode-se afirmar que houve o que comumente é chamado de "achatamento" da carreira. Isto é, elevaram-se os vencimentos iniciais com o objetivo de dar mais atratividade ao ingressante, porém não houve reprodutividade destes ajustes para os profissionais que se encontravam nas posições finais da carreira, para os professores PEB I.

No caso dos professores PEB II, ocorreu o mesmo movimento, tendo sido o ano de 1997 o com menor valor de vencimento final recebido no período $(\mathrm{R} \$ 2.026,38)$, tendo havido no ano de 1998 um aumento para $\mathrm{R} \$ 3.526,34(74,0 \%)$. Novamente, nota-se menor variação que o percentual de aumento em relação ao observado no vencimento inicial (142,7\%); assim, o mesmo "achatamento" ocorreu também para os professores PEB II.

No período subsequente, os valores dos vencimentos finais foram decrescentes até atingir, para os PEB I, em 2003, o valor de R\$1.889,95 no governo Alckmin II, e de R $\$ 2.341,15$ no ano de 2004, no mesmo governo. A partir daí, os valores oscilaram até o ano de 2009, atingindo os valores mais baixos no governo de José Serra. Mas, a partir de 2010 (governo Goldman), houve grande aumento, pois praticamente dobrou o valor dos vencimentos finais, com a introdução de mais cinco graus na carreira dos PEB I e PEB II (99, 75\%) e uma nova ampliação (29,72\%) em 2011, com tendência de leve crescimento nos anos subsequentes (governo Alckmin III). Tal condição estabeleceu uma variação de 244,67\% no período de 1996 a 2014 para o PEB I e de 228,26\% para o PEB II. Os valores corrigidos dos vencimentos finais apresentados na tabela 1 são de $\mathrm{R} \$$ 5.997,84 para o PEB I e de R\$ 6.943,28 para o PEB II.

Embora mais significativos, há que se ressaltar que existem dificuldades dentro da carreira para que tais valores de vencimentos finais sejam atingidos pelos professores da rede estadual. Em primeiro lugar, porque há uma política antiga de contratação de professores temporários na rede de ensino - através de 
um processo simplificado que não garante efetividade no cargo - que mantém esses docentes somente com seus vencimentos iniciais mais alguns adicionais. Em segundo lugar, há um número reduzido de docentes que realmente atingem essa posição no vencimento: segundo o Boletim de Pessoal da SEE-SP de 2012, havia apenas 6,92\% de professores PEB I nesse estágio e 0,80\% de docentes PEB II no último estágio da carreira. Isso claramente é um sinalizador de que existem problemas que devem ser enfrentados com mais qualidade pelas gestões e que até 2014 não haviam sido solucionados. Com isso, fica evidente que não adianta aumentar os valores finais de uma carreira se a grande maioria dos professores não conseguem atingir esse estágio.

No que tange à diferença percentual dos vencimentos por formação, particularmente na REE/SP, o valor do vencimento difere para professores com formação em nível médio na modalidade Normal e para professores especialistas. Todavia, de acordo com o estipulado nos artigos 19 e 20 da LC n 836/97, o professor PEB I que apresentar o título de formação em nível superior "salta" para a mesma condição em termos de vencimentos inicial do PEB II, mas não chega a atingir os valores de vencimentos finais que o PEB II.

Ainda sobre os dados da tabela 1, percebe-se que, num primeiro movimento, houve um crescimento da diferença percentual dos vencimentos iniciais e também dos vencimentos finais por formação, também estabelecido pela implantação da LC n ${ }^{\circ} 836 / 97$, pois as diferenças percentuais entre docentes PEB I e PEB II passam de 19,6\% e 21,6\%, respectivamente, para 25,0\% em ambos os cargos. O outro movimento foi de 2003 para 2004, quando houve mudança nos valores dos vencimentos por força da $\mathrm{LC} \mathrm{n}^{\circ}$ 958, de 13 de setembro de 2004. Com efeito, houve uma aproximação entre os valores, resultando na diferença de $15,8 \%$ tanto entre vencimentos iniciais quanto finais de docentes com diferentes formações, que permaneceu até 2014. O gráfico 1 abaixo representa melhor essa dinâmica e demonstra o "encolhimento" ocorrido na diferença percentual de vencimentos de docentes com diferentes formações. 


\section{Gráfico 1 - Variação percentual entre os vencimentos iniciais e finais de PEB I e PEB II na Rede Estadual de Ensino São Paulo entre 1996 a 2014}

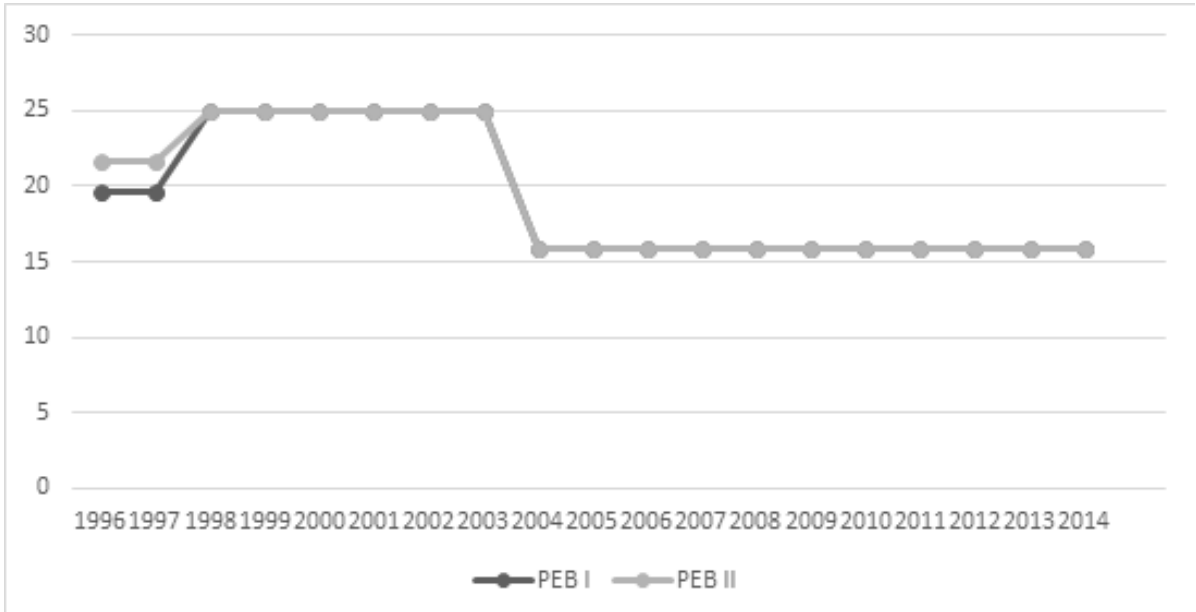

Fonte: Tabelas de Vencimentos (Anexos de Legislação) - vários anos. Valores corrigidos pelo INCPIBGE para R \$ de dez/2014.

Além disso, vale destacar que há diferentes formas de se perceber a variação dos valores iniciais e finais dos vencimentos dos docentes, ou dito de outra forma, perceber a dispersão dos valores iniciais e finais dos vencimentos dos docentes. Uma delas é basear-se num tipo de docente e calcular quanto representa a diferença entre o vencimento final e inicial considerando que esse docente permaneça na formação mínima necessária para o cargo durante toda sua carreira.

Fazendo-se cálculos com os dados da tabela 1, essa definição nos leva a perceber que a dispersão, tanto para o PEB I quanto para o PEB II, variou bastante no período. Nos anos de 1996 e 1997, os dois primeiros da série, tal dispersão era de 66,8\%. Em 1998, com o novo plano de carreira, tal dispersão caiu para 21,5\%, o que representa o já referido "achatamento" da carreira, que se manteve até o ano de 2009. No ano de 2010, dada a nova estrutura de carreira com cinco níveis e cinco graus estabelecida pela lei 1.097/2009, a dispersão entre vencimentos iniciais e finais de professores PEB I e PEB II passou a ser de 143,1\%. A partir de 2011 a dispersão passou a ser de 183,0\%.

Outra forma de perceber essas mudanças é calculando-se a dispersão total, isto é, considerando-se a variação entre a primeira posição na carreira (com o mínimo de formação e recém-contratado) e a última posição possível de ser atingida (com o máximo de tempo, máximo de formação e pontos). No caso de São Paulo considerando-se os vencimentos dos docentes, a dispersão total em 
1996 era de 102,8\%. Com a LC no 836/97, a dispersão total passou a ser de 51,9\% até 2003. De 2004 a 2009, ela caiu ainda mais, passando a ser de 40,7\%. Em 2010, invertendo a lógica anterior (governo Goldman), ela passou a ser de 181,4\% e, a partir de 2011, tem-se mantido em 227,7\% (Alckmin III).

Ademais, para aprofundarmo-nos no entendimento da dinâmica dos vencimentos da REE/SP, há de se ter também como parâmetro a lei do Piso Salarial Profissional Nacional (PSPN) (Lei n 11.738/2008), aprovada em julho de 2008 e colocada em vigor (retroativamente) a partir de 2010, após deliberação do STF sobre sua legalidade, em abril de 2011. Todavia, foi em 2011 que se ampliou ainda mais o movimento nacional em torno da questão do pagamento do PSPN. No Estado de São Paulo, contudo, a Lei do Piso não teve impacto direto no valor (porque já se pagavam valores acima deste); no entanto, aparentemente gerou efeito na obrigação do reajuste do vencimento inicial, o que também é muito importante, dado o histórico de perda nos valores corrigidos como se viu na tabela 1.

Nesse sentido, pode-se reinterpretar o aumento nos valores do vencimento inicial do PEB I entre os anos de 2010 e 2014. De 2010 a 2014, o valor do vencimento inicial de professores com formação em ensino médio foi reajustado em 19,5\%, em valores corrigidos. Já para os professores PEB II, formados em licenciatura, houve, de 2010 a 2014, aumento de aproximadamente $39,1 \%$. Aliás, importante é destacar que isso contrasta com a propaganda da Secretaria da Educação do Estado de São Paulo (SEE/SP), em seu sítio eletrônico, naquele período, pois o órgão afirmou que se valorizou o vencimento inicial dos professores em 45,1\% de 2010 a 2014.

Ainda sobre o PSPN, apresenta-se o gráfico 2. Nele se pode perceber uma tendência nítida (e rápida) da aproximação entre os vencimentos iniciais do PEB I com o PSPN (por conta da grande variação positiva deste no período de 2009 a 2014).

O que fica evidente com os dados abaixo é que, dada a aproximação dos valores dos vencimentos iniciais dos licenciados com os professores com formação de nível médio na modalidade Normal, há possibilidade - no futuro de ultrapassagem do PSPN sobre os vencimentos iniciais para professor com a menor formação aceita. Uma triste constatação para a educação do estado mais rico da nação. 
Gráfico 2 - Valores de vencimento inicial dos docentes da REE/SP (1996 2014) para 40 horas - em $R \$$ corrigidos para dez./2014.

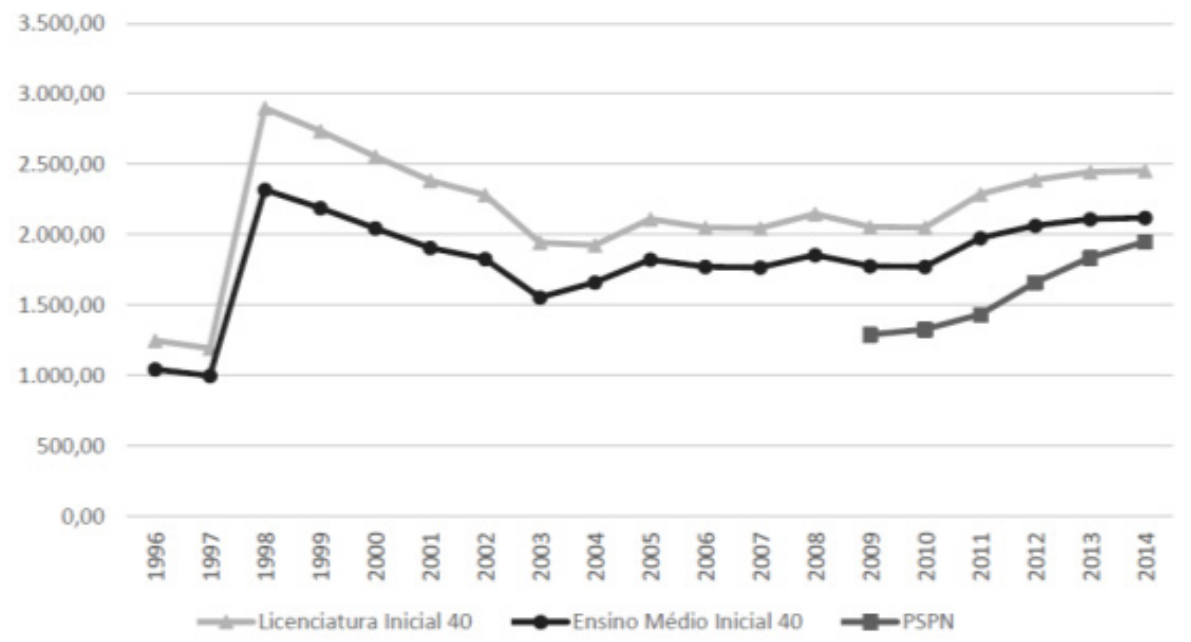

Fonte: Tabelas de Vencimentos (Anexos de Legislação) - vários anos. Valores corrigidos pelo INCPIBGE para R \$ de dez/2014.

Dado o quadro descrito e tendo em vista que o vencimento de professores na REE/SP compõe a maior parte da remuneração dos docentes, não é mero acaso que os educadores enfrentem dificuldades de sobrevivência, principalmente em situações em que a única renda familiar corresponder à remuneração desse professor, em especial nas cidades com custo de vida elevado, como São Paulo e tantas outras grandes cidades do país. Isso reforça a necessidade de muitos professores terem um segundo cargo, ou uma segunda atividade remunerada, podendo, inclusive, a própria docência ser encarada como o "bico".

Ainda, para complementar a análise dos vencimentos dos professores da REE/SP, vale apresentar o vencimento inicial dos professores com formação no Ensino Médio nacionalmente, a fim de saber qual lugar ocupa o salário de professores do estado mais rico do Brasil. Para averiguar isso mais de perto, apresenta-se a tabela 2, construída com base em dados da Confederação Nacional dos Trabalhadores em Educação (CNTE).

Explicita-se que nem todos os estados possuem jornada docente de 40 horas em suas legislações pertinentes. Em vista disso, ajustaram-se todos os vencimentos dos estados para a jornada de 40 horas e, assim, pôde-se comparálos com os dados da REE/SP apresentados até aqui. 
Tabela 2 - Tabela de vencimento inicial e valores hora-aula por formação para 40 horas (2014) em R\$ corrigidos para dez 2014

\begin{tabular}{|c|c|c|c|c|c|c|}
\hline \multirow{2}{*}{ Estado } & \multicolumn{2}{|c|}{ Ensino Médio (R\$) } & \multicolumn{2}{|c|}{ Licenciatura (R\$) } & \multirow{2}{*}{$\begin{array}{c}\text { Hora } \\
\text { atividade } \\
(\%) \\
\end{array}$} & \multirow{2}{*}{\begin{tabular}{|c|c} 
Partido da \\
Gestão em \\
2014 \\
\end{tabular}} \\
\hline & Vencimento & Hora aula & Vencimento & Hora aula & & \\
\hline Distrito Federal & $2.919,79$ & 14,6 & $3.695,93$ & 18,48 & $37 \%$ & PT \\
\hline Amapá & $2.511,86$ & 12,56 & $3.149,87$ & 15,75 & $40 \%$ & PSB \\
\hline Roraima & $2.445,52$ & 12,23 & $4.620,11$ & 23,1 & $33 \%$ & PSB \\
\hline Mato Grosso do Sul & 2.35628 & 11,78 & $3.534,42$ & 17,67 & $33 \%$ & PMDB \\
\hline Rio de Janeiro & $2.259,43$ & 11,3 & $2.702,50$ & 13,51 & $25 \%$ & PMDB \\
\hline Acre & $2.089,33$ & 10,45 & $2.680,00$ & 13,4 & $33 \%$ & PT \\
\hline Piauí & $1.965,99$ & 9,83 & $2.331,35$ & 11,66 & $33 \%$ & PMDB \\
\hline SãoPaulo & $1.950,00$ & 2,75 & $2.415,84$ & 12,08 & $17 \%$ & ESDB \\
\hline Mato Grosso & $1.739,28$ & 8,7 & $2.608,92$ & 13,04 & $33 \%$ & PMDB \\
\hline Pernambuco & $1.698,09$ & 8,49 & $1.782,99$ & 8,91 & $33 \%$ & PSB \\
\hline Pará & $1.697,67$ & 8,49 & $1.706,00$ & 8,53 & $25 \%$ & PSDB \\
\hline Paraíba & $1.697,41$ & 8,49 & $2.036,84$ & 10,18 & $33 \%$ & PSB \\
\hline Maranhão & $1.697,38$ & 8,49 & $2.162,50$ & 10,81 & $30 \%$ & PMDB \\
\hline Santa Catarina & $1.697,37$ & 8,49 & $1.706,88$ & 8,53 & $20 \%$ & PSD \\
\hline Ceara & $1.697,00$ & 8,49 & $1.705,53$ & 8,53 & $33 \%$ & PSB/PROS \\
\hline Rio Grande do Norte & $1.696,99$ & 8,48 & $2.375,79$ & 11,88 & $33 \%$ & $\mathrm{DEM}$ \\
\hline Paraná & $1.628,96$ & 8,14 & $2.327,08$ & 11,64 & $30 \%$ & PSDB \\
\hline Goiás & $1.576,40$ & 7,88 & $2.372,67$ & 11,86 & $33 \%$ & PSDB \\
\hline Tocantins & $1.567,00$ & 7,84 & $3.559,32$ & 17,8 & $40 \%$ & PSDB \\
\hline Alagoas & $1.567,00$ & 7,84 & $2.248,14$ & 11,24 & $*$ & PSDB \\
\hline Sergipe & $1.567,00$ & 7,84 & $1.794,25$ & 8,97 & $38 \%$ & PMDB \\
\hline Rondônia & $1.536,00$ & 7,68 & $2.015,00$ & 10,08 & $33 \%$ & PMDB \\
\hline Bahia & $1.451,00$ & 7,26 & $1.771,88$ & 8,86 & $30 \%$ & PT \\
\hline Minas Gerais & $1.237,01$ & 6,19 & $2.425,50$ & 12,13 & $33 \%$ & PSDB \\
\hline Rio Grande do Sul & $1.040,52$ & 5,2 & $1.924,96$ & 9,62 & $20 \%$ & PT \\
\hline Espirito Santo & 886,91 & 4,43 & $1.348,88$ & 6,74 & $33 \%$ & PSB \\
\hline Amazonas & $*$ & $*$ & $1.881,14$ & 9,41 & $*$ & PSD \\
\hline
\end{tabular}

Fonte: QUIBAO NETO, 2015, p. 200 - valores ajustados para 40 horas e corrigidos em R $\$$ para Dez/2014. * Valores não encontrados.

A primeira informação importante da tabela acima é que a posição no ranking dos vencimentos iniciais para docentes com formação de Ensino Médio na modalidade Normal não é a mesma para a formação em licenciatura. Para citar alguns casos, se colocássemos a licenciatura como a variável do ranqueamento, a rede estadual de Roraima estaria em primeiro lugar, seguido da rede do Distrito Federal e de Tocantins.

Portanto, a política de formação de professores pelas quais optam os estados diverge entre eles no que tange aos valores de vencimentos iniciais. No estado do Tocantins, por exemplo, há um alto incremento no vencimento inicial 
para professores com licenciatura, o que caracteriza claramente um incentivo para que muitos professores procurem graduar-se em busca de melhor remuneração. No caso desse estado, a diferença da hora-aula por formação é de aproximadamente R\$ 10,00. Em caso oposto está o segundo colocado da lista, a rede estadual do Amapá, cuja diferença entre a hora-aula por formação é cerca de R $\$ 3,00$.

Além disso, optamos por tomar como base o valor da Lei do Piso em maio de 2014 , que era de $\mathrm{R} \$ 1.567,00$, ou seja, o valor mínimo a ser pago por horaaula era de $\mathrm{R} \$ 7,83$ (considerando-se 40 horas aula na semana e cinco semanas no mês) para professores formados No Ensino Médio na modalidade Normal. Com tal referência, percebe-se que as redes estaduais de Rondônia ( $\mathrm{R} \$ 7,68)$, Bahia $(\mathrm{R} \$ 7,26)$, Minas Gerais $(\mathrm{R} \$ 5,20)$ e Espírito Santo $(\mathrm{R} \$ 4,43)$ ficam abaixo do valor estipulado nacionalmente. Mesmo considerando-se a formação de licenciatura, desafortunadamente o estado de Espírito Santo ( $\mathrm{R} \$ 6,74)$ estava fora da Lei do Piso no que tange ao valor.

Analisando-se a REE/SP na tabela 2, percebe-se que o valor inicial da rede de ensino está acima do Piso $(\mathrm{R} \$ 9,75)$ para formação em Ensino Médio Normal e é de R \$12,08 para formação em licenciatura. A REE/SP está em $8^{\circ}$ lugar entre os estados se compararmos o valor para formação de nível médio Normal; já para licenciatura está em $10^{\circ}$.

Ademais, vale destacar que a lei do piso prevê também o percentual de $33 \%$ da jornada de professores destinado à hora-atividade. Como se pode perceber pela tabela, a REE/SP cumpria o valor, mas não integralmente a jornada. Segundo a tabela feita pela CNTE, dos 33\% destinados à hora-atividade na jornada docente $(1 / 3)$, apenas $17 \%$ é cumprido.

A SEE/SP argumenta que a jornada do magistério paulista está de acordo com a Lei do Piso, uma vez que o contrato de seus docentes é estabelecido em horas-relógio e uma hora relógio significa 60 minutos, enquanto o tempo de trabalho com alunos, isto é, a hora-aula possui 50 (cinquenta) minutos. A diferença de 10 minutos a Secretaria contabiliza também como tempo de horaatividade. Com essa alegação, atualmente os professores da rede estadual com 40 horas de jornada semanal têm apenas 8 horas-aula para horas atividade a ser cumprida em trabalho coletivo na escola e em local de livre escolha, diferente das 14 horas-aula em hora-atividade, como seria o cálculo aproximado de 1/3 de acordo com o que prevê o PSPN. Porém, tal contabilidade das horas e horas-aula (e horas-atividade) da SEE/SP é matéria de desentendimento com a CNTE e a APEOESP. A contabilidade a partir de horas-aula acontece, contudo, há muito tempo e esse "benefício" já se solidificou como direito adquirido no passado e não pode ser usado como justificativa para não cumprir o que determina a lei do piso sobre a hora-atividade. 


\section{VENCIMENTO INICIAL, SALÁRIO MÍNIMO E O SALÁRIO MÍNIMO NECESSÁRIO}

Diante do que foi apresentado até aqui, ainda se faz necessária a comparação entre os vencimentos dos professores da REE/SP com dois importantes parâmetros salarias do país: o Salário Mínimo e o Salário Mínimo Necessário. Com isso, tem-se a pretensão de se aprofundarem algumas análises que possibilitam melhor o entendimento da política de reajuste desenvolvida pela Administração Pública do Estado de São Paulo.

O primeiro parâmetro para a comparação é o Salário Mínimo (SM) e se refere, conforme sua definição, à quantia mínima a que tem direito um trabalhador adulto, sem distinção de sexo, capaz de satisfazer, na época atual e nos diferentes pontos do país, suas necessidades normais de alimentação, habitação, vestuário, higiene e transporte. Tendo em vista a política de reajuste do SM pós anos 2000, entende-se que a relação entre os reajustes dos VI e o SM demonstra a capacidade do poder de compra de um professor da rede estadual de São Paulo e o quanto essa relação se modificou no período.

O segundo parâmetro importante é o Salário Mínimo Necessário (SMN) - DIEESE, que, por sua vez, considera o preceito constitucional de que o trabalhador, seja ele urbano ou rural, dispõe como direito um salário mínimo capaz de atender a suas necessidades vitais básicas e às de sua família com moradia, alimentação, educação, saúde, lazer, vestuário, higiene, transporte e previdência social.

Com base nos dados obtidos na legislação sobre o SM e nos estudos realizados pelo DIEESE, foipossível a elaboração de uma tabela que proporcionasse uma visão da política de reajustes desenvolvida pelas administrações públicas dos distintos governos entre 1996 e 2014.

$\mathrm{Na}$ tabela 3, é possível observar os valores do SM e do SMN, em série histórica, e a repetição dos dados sobre vencimento inicial e vencimento final para os professores com formação em Ensino Médio e para aqueles com formação em licenciatura, juntamente com as relações estabelecidas entre as variáveis citadas para análises da política de reajustes adotada:

- SMN/SM, permite interpretar o período em que houve maior arrocho salarial. Quanto maior seu valor, mais o Salário Mínimo (SM) se distanciava do Salário Mínimo Necessário (SMN);

- V.I./SM, permite apontar quantos Salários Mínimos (SM) eram precisos para compor a remuneração inicial de um professor. Quanto maior seu valor, menor poder de compra um docente obtinha no ingresso à rede de ensino. 
- V.I./SMN, permite apontar qual a fração do Salário Mínimo Necessário (SMN) em relação ao vencimento inicial (V.I.). Quanto mais próximo de 1 (um), mais a remuneração inicial supre as necessidades básicas de uma família.

\section{Tabela 3- Vencimentos Inicial e Final, Salário Mínimo, Salário Mínimo Necessário por ano e por governo, com apresentação de suas relações para docentes com distintas formações (1996-2014).}

\begin{tabular}{|c|c|c|c|c|c|c|c|c|c|c|c|c|}
\hline \multirow[b]{2}{*}{ Ano } & \multirow[b]{2}{*}{ Governo } & \multicolumn{2}{|c|}{ Ensino Mé dio } & \multicolumn{2}{|c|}{ Lice nciatura } & \multirow[b]{2}{*}{$\begin{array}{c}\text { Sal. Min } \\
\text { Naciona1 } \\
\text { (SM) } \\
{[\mathrm{e}]}\end{array}$} & \multirow{2}{*}{$\begin{array}{c}\text { Sal Min } \\
\text { Nec. } \\
\text { Dieese } \\
\text { (SMN) } \\
\text { [f] }\end{array}$} & \multirow[b]{2}{*}{$\begin{array}{c}\text { Relação } \\
\text { SMN/SM } \\
\text { [ef] }\end{array}$} & \multicolumn{2}{|c|}{ Ensino Médio } & \multicolumn{2}{|c|}{ Lice nciat ura } \\
\hline & & $\begin{array}{l}\text { V.I } \\
{[\mathrm{a}]}\end{array}$ & $\begin{array}{l}\text { V.F. } \\
\text { [b] }\end{array}$ & $\begin{array}{l}\text { V.I } \\
{[c]}\end{array}$ & $\begin{array}{l}\text { VF. } \\
\text { [d] }\end{array}$ & & & & $\begin{array}{c}\text { Relação } \\
\text { V.I/SM } \\
{[\mathrm{a} / \mathrm{e}]}\end{array}$ & $\begin{array}{c}\text { Relação } \\
\text { VI/SMN } \\
{[\mathrm{a} / \mathrm{f}]}\end{array}$ & $\begin{array}{c}\text { Relação } \\
\text { V I/SM } \\
\text { [cle] }\end{array}$ & $\begin{array}{c}\text { Relação } \\
\text { V.ISMN } \\
\text { [cf }]\end{array}$ \\
\hline 1996 & \multirow{3}{*}{ COVAS 1} & 1.043 .02 & \begin{tabular}{|l|}
1.740 .16 \\
\end{tabular} & $1.247,88$ & $2.115,18$ & \begin{tabular}{|l|l|}
344,16 \\
\end{tabular} & 2.487 .33 & 7.23 & 3.03 & 0.42 & 3,63 & 0,50 \\
\hline 1997 & & 999.24 & 1.667 .11 & 1.195 .50 & 2.026 .38 & 353.27 & 2.324 .76 & 6.58 & 2.83 & 0.43 & 3.38 & 0.51 \\
\hline 1998 & & $2.320,91$ & $2.821,05$ & $2.901,14$ & $3.526,34$ & 370,97 & $2.456,99$ & 6,62 & 6,26 & 0,94 & 7,82 & 1,18 \\
\hline 1999 & \multirow{4}{*}{$\begin{array}{l}\text { CONAS 2- } \\
\text { ALCKOIN 1 }\end{array}$} & $2.189,82$ & $2.661,70$ & $2.737,27$ & $3.327,16$ & 366,17 & $2.513,19$ & 6,86 & 5,98 & 0,87 & 7,48 & 1,09 \\
\hline 2000 & & $2.046,51$ & \begin{tabular}{|l|}
$2.487,52$ \\
\end{tabular} & $2.558,14$ & $3.109,42$ & 379,95 & $2.591,81$ & 6,82 & 5,39 & 0,79 & 6,73 & 0,99 \\
\hline 2001 & & $1.906,90$ & $2.317,83$ & $2.383,63$ & $2.897,31$ & 422,02 & $2.534,56$ & 6,01 & 4,52 & 0,75 & 5,65 & 0,94 \\
\hline 2002 & & $1.827,20$ & $2.220,94$ & $2.283,99$ & $2.776,20$ & 427,92 & $2.718,12$ & 6,35 & 4,27 & 0,67 & 5,34 & 0,84 \\
\hline 2003 & \multirow{4}{*}{$\begin{array}{l}\text { ALCKOIN 2 } \\
\text {-LPMBO }\end{array}$} & $1.554,89$ & $1.889,95$ & $1.943,60$ & $2.362,46$ & 412,41 & $2.390,91$ & 5,80 & 3,77 & 0,65 & 4,71 & 0,81 \\
\hline 2004 & & $1.663,83$ & $2.022,38$ & $1.926,08$ & $2.341,15$ & 446,78 & $2.595,91$ & 5,81 & 3,72 & 0,64 & 4,31 & 0,74 \\
\hline 2005 & & $1.822,40$ & $2.215,13$ & $2.109,64$ & $2.564,28$ & 490,99 & $2.402,99$ & 4,89 & 3,71 & 0,76 & 430 & 0,88 \\
\hline 2006 & & $1.771,65$ & $2.153,44$ & $2.050,89$ & $2.492,87$ & 556,88 & 2.402 .52 & 4,31 & 3,18 & 0,74 & 3,68 & 0,85 \\
\hline 2007 & \multirow{4}{*}{$\begin{array}{c}\text { SERRA - } \\
\text { GOLDMCAN }\end{array}$} & $1.769,51$ & $2.150,84$ & $2.048,40$ & $2.489,85$ & 576,27 & $2.726,02$ & 4,73 & 3,07 & 0,65 & 3,55 & 0,75 \\
\hline 2008 & & 1.854 .74 & $2.254,43$ & 2.147 .08 & 2.609 .78 & 587.94 & 2.854 .32 & 4.85 & 3.15 & 0.65 & 3.65 & 0.75 \\
\hline 2009 & & 1.775 .78 & 2.158 .45 & 2.055 .67 & 2.498 .68 & 630,73 & 2.829 .33 & 4.49 & 2.82 & 0.63 & 326 & 0.73 \\
\hline 2010 & & 1.773 .57 & 4.311 .56 & 2.053 .12 & 4.991 .15 & 660.84 & 2.762 .68 & 4.18 & 2.68 & 0.64 & 3.11 & 0.74 \\
\hline 2011 & \multirow{4}{*}{ ALCKAMN } & 1.975 .93 & \begin{tabular}{|l|}
5.592 .82 \\
\end{tabular} & 2.287 .38 & 6.474 .40 & 658.15 & 2.813 .69 & 4.28 & 3.00 & 0.70 & 3,48 & 0.81 \\
\hline 2012 & & 2.063 .39 & $5.840,40$ & 2.388 .64 & 6.761 .00 & 711.47 & 2.993 .80 & 4.21 & 2.90 & 0.69 & 336 & 0.80 \\
\hline 2013 & & $2.110,86$ & $5.974,75$ & $2.443,59$ & $6.916,55$ & 733,78 & $2.953,78$ & 4,03 & 2,88 & 0,71 & 3,33 & 0,83 \\
\hline 2014 & & $2.119,01$ & $5.997,84$ & $2.453,03$ & $6.943,28$ & 735,13 & $3.012,69$ & 4,10 & 2,88 & 0,70 & 3,34 & 0,81 \\
\hline
\end{tabular}

Fonte: Legislação de todo o período que a série histórica aborda. Valores corrigidos, calculados com referência ao mês de Dez/2014 pelo INPC (IBGE).

Quando avaliamos o comportamento do SM, verificamos um ganho real de $113,6 \%$ enquanto o SMN teve ganho real de 21,1\%. Esse resultado nos indica que, nesse ínterim, houve uma política de valorização do SM, o que também pode ser comprovada pela relação entre a razão entre o SMN e o SM. Podemos verificar que, em 1996, primeiro ano do estudo, a relação equivalia a 7,23, ou seja, em termos proporcionais para cada SMN, havia 7,23 SM. Em 2014, último ano da série histórica, para cada $1 \mathrm{SMN}$, havia, 4,10 SM. Isto é, podemos dizer que o maior arrocho salarial ocorreu nos anos iniciais de nossa série histórica.

Verifica-se que, na relação entre o VI e o SM, a razão entre o primeiro e o segundo saiu de um pico de 6,26 e 7,82 em 1998 para professores com Ensino Médio e professores licenciados, respectivamente. Isto é, um professor com ensino médio Normal recebia o equivalente a 6,26 SM. No final da série histórica, em 2014, esta relação alcançou o valor de 2,88 e 3,34 para professores com Ensino Médio e professores licenciados respectivamente, salvo as considerações aqui 
apontadas sobre a política de valorização do SM. Portanto, o poder de compra dos professores da REE/SP diminuiu no período analisado.

No que tange à relação entre o VI e o SMN, verifica-se que o ano de 1998 apresenta os maiores valores para a razão entre o primeiro e o segundo. Nesse primeiro ano da série histórica, os valores alcançados foram 0,94 e 1,18 para professores com formação no Ensino Médio e professores licenciados, respectivamente. Em 2014, essa relação reduziu-se para 0,70 e 0,81, ou seja, a remuneração inicial necessária para suprir as necessidades básicas de uma família foi prejudicada.

\section{CONSIDERAÇÕES FINAIS}

A partir dos dados apresentados, constata-se em primeiro lugar que o vencimento inicial tanto para a formação no Ensino Médio na modalidade Normal quanto para o professor licenciado apresentou um reajuste substancial em seus valores durante o período que corresponde ao primeiro governo de Mário Covas. É preciso ressaltar, porém, que nesse período foram incorporadas aos vencimentos as gratificações até então recebidas pelos docentes e não computadas para fins previdenciários. Isto é, os saltos nos valores de vencimentos identificam a estratégia do governo, à época, de apresentar vencimentos iniciais elevados, que, em termos concretos, indicavam maior remuneração inicial para o futuro ingressante. Assim, a estratégia adotada pelo governo citado resultou nos maiores vencimentos iniciais apresentados na série histórica do artigo, considerando-se valores corrigidos.

Após esse ano de 1998, a dinâmica apresentada revelou uma tendência de decrescimento dos valores dos vencimentos iniciais para as duas formações, que vai até meados de 2003, no segundo governo de Geraldo Alckmin, quando se inicia um período praticamente sem aumento real até o ano de 2010. Depois, a dinâmica dos vencimentos apresentou um crescimento que tende a diminuir até estabilizar em 2014.

Em termos percentuais, os ganhos reais - consideradas as correções do INPC - do vencimento inicial dos docentes da REE/SP com formação de Ensino Médio foram de 103,2 \%, enquanto os de um professor licenciado foram de 96,6 $\%$ em todo o período da série histórica.

Ainda, os dados apontam que o Estado mais rico do Brasil não é aquele que melhor paga inicialmente os professores de sua rede básica em termos de vencimento, uma vez que a REE/SP está em $8^{\circ}$ lugar entre os estados quando se conta o valor para formação de nível médio; já para licenciatura está em $10^{\circ}$. 
Observa-se, ainda pelas relações entre o VI, SM e SMN. que o professor, tanto aquele cuja formação é Ensino Médio Normal, quanto aquele com formação em licenciatura, tem perdido seu poder de compra e sendo prejudicado no que tange à remuneração inicial mínima para suprir as necessidades básicas de sua família.

Por fim, outra preocupante constatação é a aproximação entre os vencimentos iniciais para professores com formação média normal (PEB I) com o PSPN, e considerando-se a série histórica e essa rápida aproximação, há possibilidade de ultrapassagem entre o PSPN sobre os vencimentos iniciais desses professores.

\section{REFERÊNCIAS}

ARELARO, Lisete Regina. O ensino fundamental no Brasil: avanços, perplexidades e tendências. Educ. Soc., Campinas, vol. 26, n. 92, p. 1039-1066, Especial - Out. 2005. Disponível em: < http://www.cedes.unicamp.br/ > Acesso em: 21 de abril de 2016.

BRASIL. Constituição Federal de 1988. Disponível em < http://www.planalto. gov.br>. Acesso em: 10 Abr./2016.

Decreto-Lei $\mathrm{n}^{\mathrm{o}}$ 2.162, de $1^{\mathrm{o}}$ de maio de 1940. Institui o salário mínimo e dá outras providências, 1940. Disponível em < http://www2.camara. leg.br/legin/fed/declei/1940-1949/decreto-lei-2162-1-maio-1940-412194publicacaooriginal-1-pe.html>. Acesso em: 10 Abr./2016.

Lei $\mathbf{n}^{\circ} \mathbf{1 1 . 7 3 8}$ de 16 de Julho de 2008. Regulamenta a alínea "e" do inciso III do caput do art. 60 do Ato das Disposições Constitucionais Transitórias, para instituir o piso salarial profissional nacional para os profissionais do magistério público da educação básica.

DIEESE.MetodologiadaCestaBásicadeAlimentos.SãoPaulo,2009.Disponível em: https://www.dieese.org.br/metodologia/metodologiaCestaBasica.pdf.

JACOMINI, M.A.; MINHOTO, M.A.; CAMARGO, R.B. Financiamento da educação e remuneração docente na educação básica: uma abordagem a partir de planos de carreira, vencimentos e composição remuneratória em 2010. Porto Alegre: Revista Fineduca, Volume 2, n.10, 2012. 
NASCIMENTO, A.P.S.; MEDINA, R.R.A; CAMARGO, R.B. Composição salarial dos docentes da rede estadual paulista - uma análise a partir do Boletim de Acompanhamento de Pessoal da SEE-SP - 1996 - 2010. In:. IV Congresso Ibero Americano de Política e Administração da Educção. Porto: Cadernos da ANPAE, 2014. v. 18.

QUIBAO NETO, José. Docentes não concursados na Rede Estadual de Ensino de São Paulo: ordenamento jurídico, perfil e remuneração. 2015. 240 f. Dissertação (Mestrado em Educação). Universidade de São Paulo, Ribeirão Preto, 2015.

SÃO PAULO (Estado). Decreto n ${ }^{\circ} \mathbf{5 4 . 2 9 7}$, de 5 de maio de 2009. Cria a Escola de Formação e Aperfeiçoamento dos Professores do Estado de São Paulo e dá outras providências. São Paulo, 2009a. Disponível em: <http://www.jusbrasil. com.br/legislacao/231417/decreto-54297-09-sao-paulo-sp>. Acesso em: 6 maio 2012.

Decreto $\mathrm{n}^{\circ}$ 55.217, de 21 de dezembro de 2009. Regulamenta a Lei Complementar $\mathrm{n}^{\circ} 1.097$, de 27 de outubro de 2009, que institui o sistema de promoção para os integrantes do Quadro do Magistério da Secretaria da Educação e dá outras providências. São Paulo, 2009b. Disponível em: <http:// www.jusbrasil.com.br/legislacao/820943/decreto-55217-09-sao-paulo-sp>. Acesso em: 6 maio 2012.

Lei Complementar $\mathrm{n}^{\circ}$ 836, de 30 de dezembro de 1997. Institui Plano de Carreira, Vencimentos e Salários para os integrantes do Quadro do Magistério da Secretaria da Educação e dá outras providências correlatas. São Paulo, 1997. Disponível em: <http://www.jusbrasil.com.br/legislacao/anotada/3426973/lc838-97-sao-paulo>. Acesso em 10 mar. 2012.

Lei Complementar $\mathrm{n}^{\circ} 1.097$, de 27 de outubro de 2009. Institui o sistema de promoção para os integrantes do Quadro do Magistério da Secretaria da Educação e dá outras providências. São Paulo, 2009c. Disponível em: <www. legislacao.sp.gov.br/legislacao/dg280202.nsf/.../C-1097.doc>. Acesso em: 5 dez.2010. 
Lei Complementar $\mathrm{n}^{\mathbf{0}} \mathbf{1 . 1 4 3}$, de 11 de julho de 2011. Dispõe sobre a reclassificação de vencimentos e salários dos integrantes do Quadro do Magistério da Secretaria da Educação, e dá providências correlatas. São Paulo, 2011. Disponível em: < http://www.al.sp.gov.br/repositorio/legislacao/lei. complementar/2011/lei.complementar-1143-11.07.2011.html > Acesso em: 5 maio 2012.

. Resolução SE n⿳ 21, de 22 de março de 2005. Dispõe sobre a Evolução Funcional pela via não acadêmica, dos integrantes do Quadro do Magistério. São Paulo, 2005. Disponível em: <http://www.dersv.com/res21_evol_nao_acad. htm>. Acesso em: 5 maio 2012.

INSTITUTO BRASILEIRO DE GEOGRAFIA E ESTATÍSTICA. Disponível em: < http://www.ibge.gov.br/estadosat/perfil.php?sigla=sp > Acesso em: 21 de abril de 2016.

RUBENS BARBOSA DE CAMARGO atualmente é Professor Doutor da Universidade de São Paulo, foi Conselheiro do Conselho Municipal de Educação de São Paulo (2001 a 2008) e Conselheiro do Conselho de Acompanhamento e Controle Social do Fundef do Município de S. Paulo (2004 a 2008). ExSecretário Municipal de Educação e Cultura do Município de São Carlos (2001) e do Município de Suzano (2005 e 2006).E-mail: rubensbc@usp.br

JOÃO BATISTA SILVA DOS SANTOS é licenciado em Física pela Universidade de São Paulo e Mestre em Políticas educacionais e Formação de Professores pelo Programa de pós-graduação em Educação - UNIFESP, atua como professor na Rede de Ensino Básico do Estado de São Paulo. Realiza pesquisa na área de políticas públicas em educação com ênfase em financiamento escolar, remuneração docente e condições precárias. E-mail: santos.jbatista@gmail.com

JOSÉ QUIBAO NETO é doutorando na Faculdade de Educação da Universidade de São Paulo e atua como professor de Língua Portuguesa e Literatura na rede básica de ensino. Realiza pesquisa na área de políticas educacionais, com ênfase em financiamento escolar, remuneração docente das redes básicas, condição de trabalho e contratação de professores. E-mail: jose.quibao.neto@usp.br

Recebido em agosto de 2016 Aprovado em setembro de 2016 